\title{
The Crystal Structure of $\mathrm{NaGa}_{11} \mathrm{O}_{16}(\mathrm{OH})_{2}$
}

\section{A. NØRLUND CHRISTENSEN}

Department of Inorganic Chemistry, Aarhus University, DK-8000 Aarhus C, Denmark

The compound $\mathrm{NaGa}_{11} \mathrm{O}_{16}(\mathrm{OH})_{2}$ was prepared using hydrothermal techniques. $\mathrm{X}$-Ray diffraction shows the compound to be monoclinic, the space group is $P 2_{1} / m$ with $a=8.602(5) \AA$, $b=8.906(5) \AA, \quad c=9.571(4) \AA, \quad \beta=117.1(2)^{\circ}$; there are 2 formula units per cell.

Least squares refinement with 801 reflections gave a final $R$-value of $7.5 \%$ for 73 parameters. The intensity data were collected on an automatic diffractometer using monochromatized $\mathrm{Cu} K \alpha$-radiation.

The structure contains $\mathrm{GaO}_{6}$ octahedra and $\mathrm{GaO}_{4}$ tetrahedra. The mean gallium-ogygen distance within the octahedra is $2.00 \AA$, $\sigma=0.01 \AA$, while the mean gallium-oxygen distance within the tetrahedra is $1.85 \AA$, $\sigma=0.01 \AA$.

A high pressure high temperature hydrothermal investigation of metal oxides has resulted in preparation of dense metal oxide hydroxides with crystal structures of the indium oxide hydroxide type or of the tetragonal type of the ytterbium oxide hydroxide structure. ${ }^{1-4}$

The hydrothermal investigation of the $\mathrm{Ga}_{2} \mathrm{O}_{3}$. $\mathrm{H}_{2} \mathrm{O}-\mathrm{Na}_{2} \mathrm{O}$ system yielded a monoclinic compound of unknown composition. ${ }^{1}$ A threedimensional X-ray analysis has shown that this compound, which in Ref. 1 was called a gallium hydroxide phase, $[\mathrm{Ga}(\mathrm{I})]$, has the formula $\mathrm{NaGa}_{11} \mathrm{O}_{16}(\mathrm{OH})_{2}$.

\section{EXPERIMENTAL}

The preparation of $\mathrm{NaGa}_{11} \mathrm{O}_{18}(\mathrm{OH})_{2}$, together with its $\mathrm{X}$-ray powder pattern, is given in Ref. 1 . The crystal used was $0.012 \mathrm{~cm}$ in length and 0.004 by $0.004 \mathrm{~cm}$ in cross section. It was mounted with its [010] axis as rotation axis, and was investigated using Weissenberg and precession methods. Only the reflections $0 k 0$ with $k=2 n+1$ were absent, indicating the space group $P 2_{1}$ or $P 2_{1} / m$. A total of 801 independent $h k l$ reflections with $I>2 \sigma(I)$ were measured with a Picker diffractometer, using $\mathrm{Cu} K \alpha$ radiation monochromatised by reflection from a graphite crystal and a scintillation counter in conjunction with a pulse height analyzer. Lorentz-polarization corrections were applied and a correction was made for absorption using Well's method. ${ }^{5}$

\section{STRUCTURE DETERMINATION}

The space group $P 2_{1} / m$ (No. 11) has been used in the structure determination. The structure was solved using direct methods. The program SYMBAD ${ }^{6}$ was used to normalize the structure factors and the program MULTAN ? to determine four sets of phases for 152 reflections. Using the program JIMDAP, ${ }^{8}$ threedimensional Fourier maps were calculated, and those showing positions of heavy atoms at $(0.35,0.60,0.05),(0.35,0.25,0.05),(0.35,0.10$, $0.35),(0.35,0.75,0.35),(0.95,0.60,0.25)$, and $(0.70,0.10,0.35)$ were used. After a series of refinement cycles and Fourier calculations all the atoms required by the formula $\mathrm{NaGa}_{11} \mathrm{O}_{16}(\mathrm{OH})_{2}$, except the hydrogen atoms, were located. Refinement was carried out with the Fortran crystallographic least squares program LINUS, ${ }^{9}$ using isotropic temperature coefficients and the refinement converged at a conventional $R$-value of $7.5 \%$. Parameters refined were atomic coordinates, thermal parameters, and two scale factors.

\section{CRYSTAL DATA}

The formula of the compound is $\mathrm{NaGa}_{11} \mathrm{O}_{16}$. $(\mathrm{OH})_{2}$, and the unit cell contains two formula units. The crystal system is monoclinic, and the space group is $P 2_{1} / m$ (No. 11). The unit

Acta Chem. Scand. A 28 (1974) No. 2 
Table 1. Atomic coordinates and temperature factors for $\mathrm{NaGa}_{11} \mathrm{O}_{16}(\mathrm{OH})_{2}$, with their standard deviations.

\begin{tabular}{lllll}
\hline Atom $x / a$ & $y / b$ & $z / c$ & $B\left(\AA^{2}\right)$ \\
\hline & & & & \\
$\mathrm{Na}_{1}$ & $0.041(1)$ & 0.25 & $0.057(1)$ & $1.7(2)$ \\
$\mathrm{Ga}_{1}$ & $0.3679(3)$ & $0.5771(3)$ & $0.0490(2)$ & $0.77(6)$ \\
$\mathrm{Ga}_{2}$ & $0.3727(4)$ & 0.25 & $0.0465(3)$ & $0.74(7)$ \\
$\mathrm{Ga}_{3}$ & $0.3471(3)$ & $0.0848(3)$ & $0.3597(2)$ & $0.76(6)$ \\
$\mathrm{Ga}_{4}$ & $0.3600(4)$ & 0.75 & $0.3615(4)$ & $0.86(7)$ \\
$\mathrm{Ga}_{5}$ & $0.9698(3)$ & $0.5786(3)$ & $0.2579(2)$ & $0.79(6)$ \\
$\mathrm{Ga}_{6}$ & $0.7133(3)$ & $0.0760(3)$ & $0.3469(2)$ & $0.77(6)$ \\
$\mathrm{Ga}_{7}$ & $0.8877(4)$ & 0.75 & $0.5404(4)$ & $0.74(7)$ \\
$\mathrm{O}_{1}$ & $0.612(1)$ & $0.083(1)$ & $0.478(1)$ & $0.2(2)$ \\
$\mathrm{O}_{2}$ & $0.368(2)$ & 0.25 & $0.509(2)$ & $0.7(3)$ \\
$\mathrm{O}_{3}$ & $0.341(2)$ & $0.582(1)$ & $0.231(1)$ & $0.4(2)$ \\
$\mathrm{O}_{4}$ & $0.338(2)$ & 0.25 & $0.230(2)$ & $0.5(3)$ \\
$\mathrm{O}_{5}$ & $0.554(1)$ & $0.081(1)$ & $0.130(1)$ & $0.0(2)$ \\
$\mathrm{O}_{6}$ & $0.546(2)$ & 0.75 & $0.120(2)$ & $0.1(3)$ \\
$\mathrm{O}_{7}$ & $0.098(1)$ & $0.091(1)$ & $0.305(1)$ & $0.0(2)$ \\
$\mathrm{O}_{8}$ & $0.847(2)$ & 0.25 & $0.368(2)$ & $0.6(3)$ \\
$\mathrm{O}_{9}$ & $0.794(1)$ & $0.584(1)$ & $0.050(1)$ & $0.1(3)$ \\
$\mathrm{O}_{10}$ & $0.849(1)$ & $0.593(1)$ & $0.376(1)$ & $0.2(2)$ \\
$\mathrm{O}_{11}$ & $0.097(2)$ & 0.75 & $0.282(2)$ & $0.4(3)$ \\
$\mathrm{O}_{12}$ & $0.784(2)$ & 0.25 & $0.052(2)$ & $0.8(4)$ \\
\hline
\end{tabular}

Table 2. Interatomic distances $(\AA)$ and bond angles (degrees). Standard deviations in parentheses.

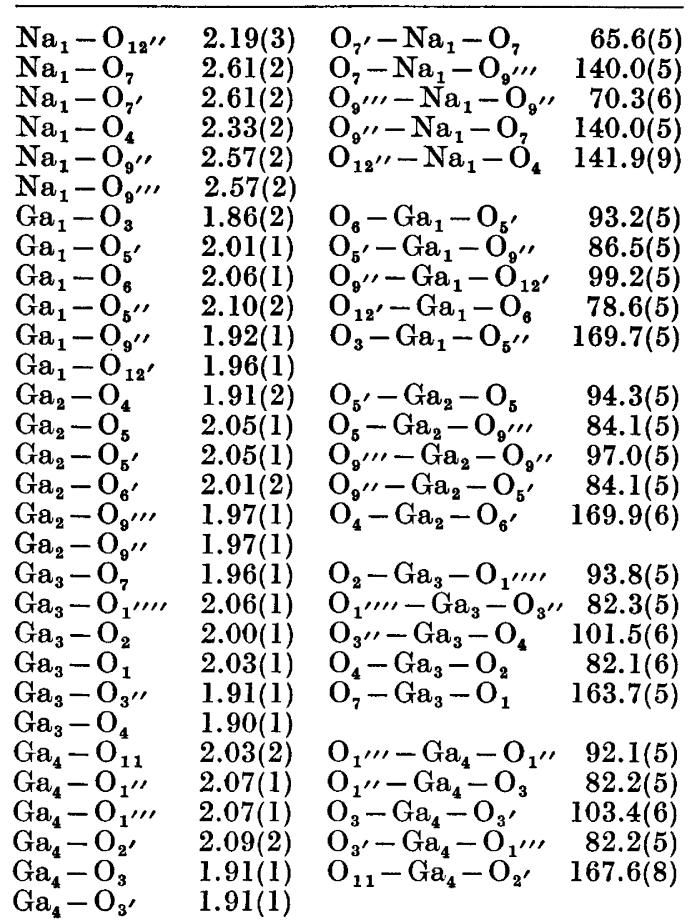

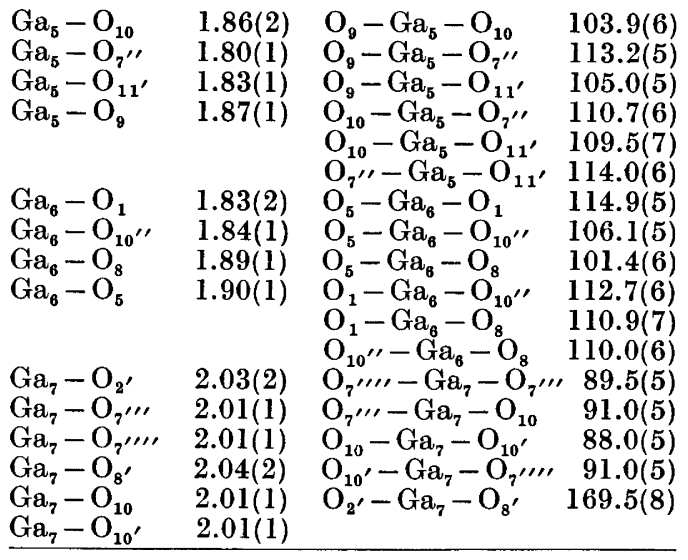

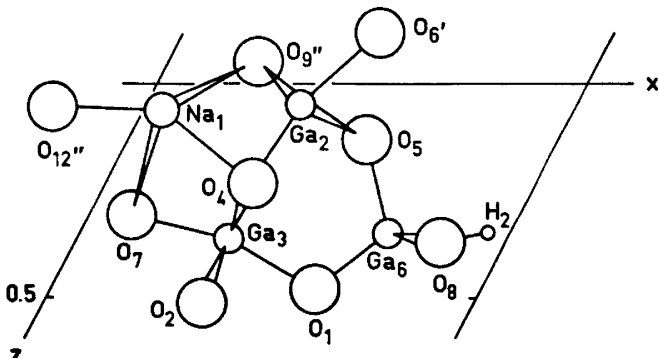

Fig. 1. Projection of metal-oxygen coordination polyhedra on (010). The $y$ coordinates of the metal atoms are: $\mathrm{Na}_{1}(0.25), \mathrm{Ga}_{2}(0.25), \mathrm{Ga}_{3}$ $(0.0848)$, and $\mathrm{Ga}_{6}(0.0760)$. $\mathrm{O}_{3^{\prime}}$ is covered by $\mathrm{O}_{4}, \mathrm{O}_{1 \prime \prime \prime \prime}$ by $\mathrm{O}_{2}$, and $\mathrm{O}_{10^{\prime \prime}}$ by $\mathrm{O}_{8} . \mathrm{O}_{5^{\prime}}$ is over $\mathrm{O}_{5}$, and $\mathrm{O}_{9 \prime \prime}^{\prime \prime}$ is over $\mathrm{O}_{9}^{\prime \prime}$. (The atoms with primes after the suffix numbers are symmetry related to the atoms with the same suffix number of which atom the coordinates are listed in Table 1).

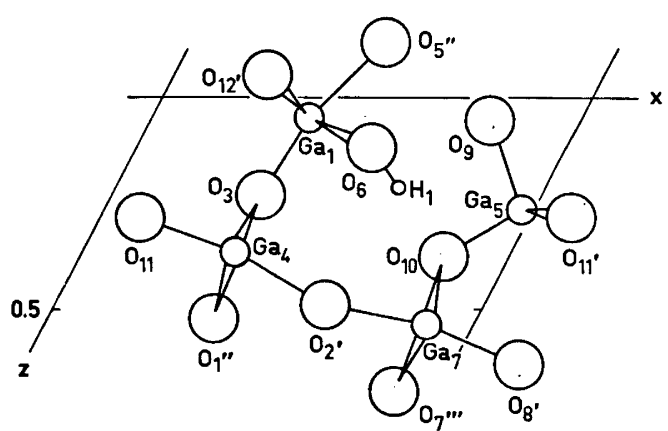

Fig. 2. Projection of metal oxygen coordination polyhedra on $(010)$. The $y$ coordinates of the metal atoms are: $\mathrm{Ga}_{4}(0.75), \mathrm{Ga}_{7}(0.75)$, $\mathrm{Ga}_{1}$ $(0.5771)$, and $\mathrm{Ga}_{5}(0.5786)$. $\mathrm{O}_{9^{\prime \prime}}$ is covered by $\mathrm{O}_{12^{\prime}}, \mathrm{O}_{5^{\prime}}$ by $\mathrm{O}_{6}$, and $\mathrm{O}_{7^{\prime \prime}}$ by $\mathrm{O}_{11^{\prime}} \cdot \mathrm{O}_{3^{\prime}}$ is over $\mathrm{O}_{3}, \mathrm{O}_{1^{\prime \prime}}$ is over $\mathrm{O}_{1^{\prime \prime}}, \mathrm{O}_{10^{\prime}}$ is over $\mathrm{O}_{10}$, and $\mathrm{O}_{7}^{\prime \prime \prime \prime}$ is over $\mathrm{O}_{7}^{\prime \prime \prime}$.

Acta Chem. Scand. A 28 (1974) No. 2 
Table 3. Observed and calculated structure factors. Reading from left to right, the columns are $h, k, l, F_{\text {obs }}, F_{\text {calc }}$.
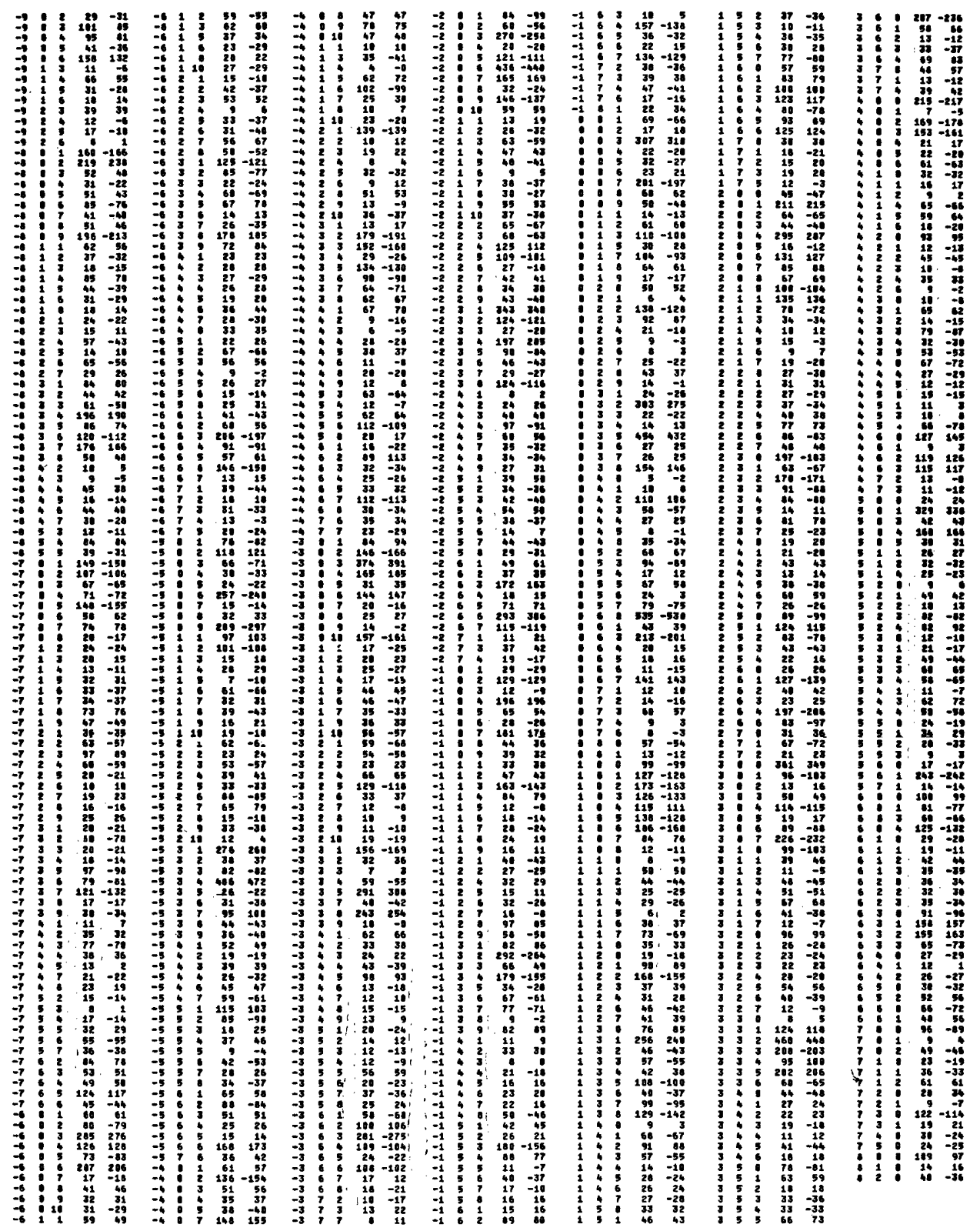

cell parameters are $a=8.602(5) \AA, b=8.906(5)$ $\AA, c=9.571(4) \quad \AA$, and $\beta=117.1(2)^{\circ}$. The calculated density is $5.52 \mathrm{~g} / \mathrm{cm}^{3}$, and the absorption coefficient for $C u$-radiation is $287 \mathrm{~cm}^{-1}$. The structure factors for the atoms were Acta Chem. Scand. A 28 (1974) No. 2 calculated from atomic scattering factors reported by Cromer and Mann. ${ }^{10}$ Atomic coordinates and temperature factors are listed in Table 1, interatomic distances and bond angles in Table 2, and observed and calculated 

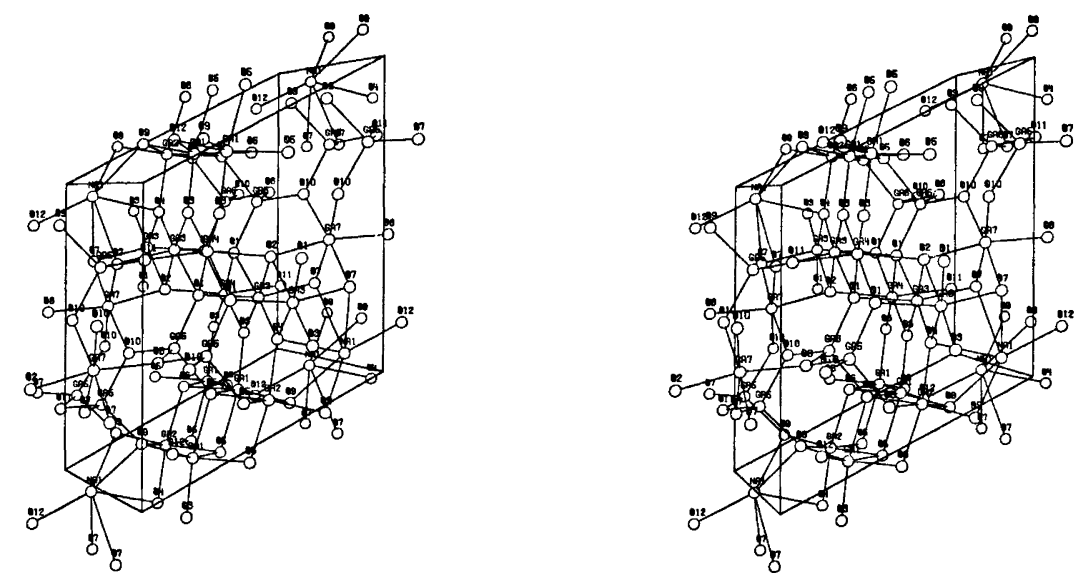

Fig. 3. Three-dimensional model of the crystal structure of $\mathrm{NaGa}_{11} \mathrm{O}_{16}(\mathrm{OH})_{2}$.

structure factors in Table 3. Fig. 1 is a projection on (010) showing the metal-oxygen coodination polyhedra for the metal atoms $\mathrm{Na}_{1}, \mathrm{Ga}_{2}$, $\mathrm{Ga}_{3}$, and $\mathrm{Ga}_{6}$, and Fig. 2 is a projection on (010) showing the coordination polyhedra for the metal atoms $\mathrm{Ga}_{1}, \mathrm{Ga}_{4}, \mathrm{Ga}_{5}$, and $\mathrm{Ga}_{7}$. Fig. 3 shows a three-dimensional model of the structure.

\section{DISCUSSION}

The crystal structure of $\mathrm{NaGa}_{11} \mathrm{O}_{18}(\mathrm{OH})_{2}$ contains $\mathrm{GaO}_{6}$ octahedra and $\mathrm{GaO}_{4}$ tetrahedra The $\mathrm{Ga}_{1}, \mathrm{Ga}_{2}, \mathrm{Ga}_{3}, \mathrm{Ga}_{4}$, and $\mathrm{Ga}_{7}$ atoms are coordinated by six oxygen atoms, while the $\mathrm{Ga}_{5}$ and $\mathrm{Ga}_{6}$ atoms are coordinated by four oxygen atoms. The $\mathrm{GaO}_{6}$ octahedra are distorted and resemble the octahedra found in the diaspore modification of $\mathrm{GaOOH}{ }^{11}$ and of AlOOH.12 The distances from gallium to oxygen within the octahedra have a mean of $2.00 \AA$, $\sigma=0.01 \AA$, in good agreement with the $\mathrm{Ga}-\mathrm{O}$ distances of $2.00 \AA$ found in the $\mathrm{GaO}_{6}$ octahedra of the $\beta \cdot \mathrm{Ga}_{2} \mathrm{O}_{3}$ structure. ${ }^{13}$ The $\mathrm{GaO}_{4}$ tetrahedra are fairly regular and the gallium oxygen distances have a mean of $1.85 \AA, \sigma=0.01 \AA$, also in good agreement with the $\mathrm{Ga}-\mathrm{O}$ distance of $1.834 \AA$ found in the $\mathrm{GaO}_{4}$ tetrahedra of the $\beta$ - $\mathrm{Ga}_{2} \mathrm{O}_{3}$ structure. ${ }^{13}$ The sodium atom is coordinated by six oxygen atoms in a rather distorted octahedron, the $\mathrm{Na}-\mathrm{O}$ distances having a mean of $2.48 \AA, \sigma=0.02 \AA$.

The oxygen atoms $\mathrm{O}_{1}, \mathrm{O}_{2}, \mathrm{O}_{4}, \mathrm{O}_{5}, \mathrm{O}_{7}$, and $\mathrm{O}_{9}$ are tetrahedrally coordinated by metal atoms, and the oxygen atoms $\mathrm{O}_{3}, \mathrm{O}_{6}, \mathrm{O}_{8}, \mathrm{O}_{10}, \mathrm{O}_{11}$, and $\mathrm{O}_{12}$ are each coordinated by three metal atoms giving coordination polyhedra with geometries close to that of an ammonia molecule. It was not possible to determine the positions of the two hydrogen atoms from the last difference Fourier. It is, however, likely that the hydrogen atoms are bonded to two of the four oxygen atoms: $\mathrm{O}_{6}, \mathrm{O}_{8}, \mathrm{O}_{11}$, and $\mathrm{O}_{12}$ which are all situated on mirror planes. From packing considerations it is suggested that one hydrogen atom at $(0.66,0.75,0.21)$ is bonded to $\mathrm{O}_{6}$, and the other hydrogen atom at $(0.94,0.25,0.34)$ is bonded to $\mathrm{O}_{8}$.

The temperature factor coefficients for the oxygen atoms are within three standard deviations similar to the temperature factor coefficients of the gallium atoms. It is normally found in oxide structures where the metal oxygen coordination polyhedra have a dense packing, that the temperature factor coefficients of the metal atoms and of the oxygen atoms are of the same order of magnitude. ${ }^{14,15}$

The compound was not a pure gallium hydroxide phase as assumed in Ref. 1, but was a sodium gallium oxide hydroxide. It has a rather dense packing of atoms in the structure and the density of the compound is comparable with that of $\beta-\mathrm{Ga}_{2} \mathrm{O}_{3}$. The stacking of the $\mathrm{GaO}_{6}$ coordination octahedra found in this structure is similar to the stacking of the octahedra in the $\beta-\mathrm{Ga}_{2} \mathrm{O}_{3}$ structure. ${ }^{13}$ Although the formula of the compound $\mathrm{NaGa}_{11} \mathrm{O}_{16}(\mathrm{OH})_{2}$ resembles that of $\beta$-alumina,

Acta Chem. Scand. A 28 (1974) No. 2 
$\mathrm{NaAl}_{11} \mathrm{O}_{17}$, and that of the isomorphous gallium compound, $\mathrm{NaGa}_{11} \mathrm{O}_{17}$, the crystal structures of these two compounds ${ }^{16,17}$ are different from that of $\mathrm{NaGa}_{11} \mathrm{O}_{16}(\mathrm{OH})_{2}$.

\section{REFERENCES}

1. Christensen, A. N. Mater. Res. Bull. 6 (1971) 691 .

2. Christensen, A. N. Acta Chem. Scand. 24 (1970) 3074.

3. Gondrand, M. and Christensen, A. N. Mater. Res. Bull. 6 (1971) 239.

4. Christensen, A. N. and Hazell, R. G. Acta Chem. Scand. 26 (1972) 1171.

5. Wells, M. J. Acta Crystallogr. 13 (1960) 722.

6. Danielsen, J. $S Y M B A D, A$ program for direct methods in crystalloghraphy, 1972, Department of Chemistry, Aarhus University, DK-8000 Aarhus C.

7. Germain, G., Université de Louvain, Louvain, Belgique, Woolfson, M. M. and Main, P., University of York, York, England, Computer program $M U L T A N$, $19 \% 1$.

8. Zalkin, A., University of California, Berkeley, California, $J I M D A P$ is a Brookhaven version of the Zalkin FORDAP program, 1971.

9. Busing, W. R., Martin, K. O. and Levy, H. A. (1962), ORFLS, A Fortran Crystallographic Least Squares Program, Oak Ridge National Laboratory Report, ORNL-TM305. LINUS is a 1971 version of ORFLS.

10. Cromer, D. T. and Mann, J. B. Acta Crystallogr. A 24 (1968) 321.

11. Roy, R., Hill, V. G. and Osborn, E. F. J. Amer. Chem. Soc. 74 (1952) 719.

12. Busing, W. R. and Levy, H. A. Acta Crystallogr. 11 (1958) 798.

13. Geller, S. J. Chem. Phys. 33 (1960) 676.

14. Lehmann, M. S., Larsen, F. K., Poulsen, F. R., Christensen, A. N. and Rasmussen, S. E. Acta Chem. Scand. 24 (1970) 1662.

15. Christensen, A. N. Acta Chem. Scand. 26 (1972) 1955.

16. Beevers, C. A. and Ross, M. A. S. Z. Kristallogr. 97 (1937) 59.

17. Foster, L. M. and Stumpf, H. C. J. Amer. Chem. Soc. 73 (1951) 1590.

Received September 11, 1973. 